\title{
Portföy Seçiminde Analitik Hiyerarşi Sürecinin Kullanılması: Kantitatif ve Temel Analizi Birleştiren Hibrit Bir Yaklaşım
}

\author{
Furkan GÖKTAŞ \\ orcid.org/0000-0001-9291-3912 \\ Dr. Öğr. Üyesi, Karabük Üniversitesi, İşletme Fakültesi \\ Asst. Prof. Dr., Karabuk University, Faculty of Business \\ furkangoktas@karabuk.edu.tr
}

\section{Öz}

Portföy seçiminde kantitatif ve temel analizin birlikte dikkate alınması yararlı olabilir. Bu nedenle bu tür analizleri birleştiren hibrit bir yaklaşım bu çalışmada önerilmiştir. Önerilen yaklaşım Analitik Hiyerarşi Sürecine (AHS) dayanmaktadır ve BIST 30'daki bankacılık hisselerine ait veri seti kullanılarak tanıtılmıştır. Ayrıca önerilen yaklaşımdan ve literatürdeki alternatiflerinden elde edilen geriye dönük test sonuçları karşılaştırılmıştır. Yapılan uygulamada eğitim periyodu 2016'nın son üç ayı ve 2017'nin ilk on ayından oluşmakta iken test periyodu 2017'nin son iki ayından oluşmaktadır.

Anahtar Kelimeler: Portföy Seçimi, Analitik Hiyerarşi Süreci, Temel Analiz, Ortalama - Varyans Modeli, BIST.

\section{Using Analytical Hierarchy Process in Portfolio Selection: A Hybrid Approach Combining the Quantitative and Fundamental Analyses}




\section{Abstract}

It may be useful to consider the quantitative and fundamental analyses together in portfolio selection. Thus, a hybrid approach combining these type of analyses is proposed in this study. The proposed approach is based on Analytical Hierarchy Process (AHP) and illustrated by using a data set of banking stocks in BIST 30. The backtesting results of the proposed approach and its alternatives in the literature are also compared. In the application, testing period consists of last two months of 2017 while training period consists of last three months of 2016 and first ten months of 2017.

Keywords: Portfolio Selection, Analytical Hierarchy Process, Fundamental Analysis, Mean - Variance Model, BIST.

\section{Giriş}

Riskin dağıtımı ve çeşitlendirme, Markowitz (1952)'de verilen Ortalama - Varyans (OV) modelinden bu yana finansal yatırımların merkezindedir. Öte yandan Breuer (2006)'da verildiği üzere portföy yöneticileri genellikle OV Modeli gibi optimizasyon modelleri yerine kişisel yargılarıyla karar vermektedir. Çünkü parametrelerin (OV modelinde ortalama vektörü ve kovaryans matrisin) tahmin edilmesi oldukça zor olduğundan örneklem dışı yapılan analizlerde düşük performans elde edilmektedir (Garlappi ve diğerleri, 2006). Ayrıca tahmin edilen parametreler piyasa şokları ile değişebilmektedir (Jorion, 2007). Bununla birlikte portföy yöneticisi, temel analize dayanan farklı kriterlerin de bu süreçte etkili olmasını isteyebilir (Saaty ve diğerleri, 1980; Tiryaki ve Ahlatçıŏlu, 2009). Bu nedenle bu çalışmada kantitatif analizi ve temel analizi birlikte dikkate alan ve 
Analitik Hiyerarşi Sürecine (AHS) dayanan hibrit bir yaklaşım önerilmiştir.

Bu çalışmanın ana hatları şu şekildedir. Bölüm 1'de OV modeli açıklanmıştır. Bölüm 2'de AHS ile portföy seçimi ve önerilen yaklaşım açıklanmıştır. Bölüm 3'te önerilen yaklaşım bir uygulama ile tanıtılmıştır. Burada BIST 30 bankacılık hisselerinin 2016 Ekim'den 2017 Kasım'a kadarki 13 aylık veri seti kullanılarak, 2017 Kasım ve Aralık aylarını kapsayan periyot için portföy seçimi yapılmış ve elde edilen sonuçlar literatürdeki alternatiflerinden elde edilen sonuçlarla kıyaslanmıştır. Makalenin sonunda, çalışmanın sonuçları özetlenmiş ve son değerlendirmeler yapılmıştır.

\section{Ortalama - Varyans Modeli}

$\mathrm{Bu}$ çalışmada kısa pozisyon almanın getirdiği ek maliyetler ihmal edilmiştir. Ayrıca logaritmik getiri vektörünün (r) dağılımının ortalama vektörü $\mu$, kovaryans matris $\sum$ ile çok değişkenli normal olduğu varsayılmıştır. Bu varsayım hisse senetlerinin fiyatlarının modellenmesinde kullanılan Çok Boyutlu Geometrik Brownian Harekete dayanır. Buna göre ortalama vektörü ve kovaryans matris, zamanın lineer (doğrusal) fonksiyonudur. Başka bir deyişle elde tutma periyotunun süresi arttıkça portföyün beklenen getirisi ve varyansı da lineer olarak artar (Brigo ve diğerleri, 2007).

OV modeli aşağıdaki çok amaçlı konkav maksimizasyon problemi ile verilir. Portföyün ağırlık vektörü $w$ ile gösterilmiştir ve uygun çözüm kümesi (S) kapalı ve konvekstir. Burada birinci amaç portföyün beklenen getirisini maksimum yapmak iken ikinci amaç portföyün riskini minimum yapmaktır (Markowitz, 1952). 


$$
\operatorname{maks}_{w \in S}\left\{\begin{array}{l}
\mu_{p}:=w^{T} \mu \\
-\sigma_{p}^{2}:=-w^{T} \Sigma w
\end{array}\right\}
$$

Ağırlıklı amaç metodu konkav maksimizasyon problemleri için etkin sınırı tam olarak verir (Deb, 2001). r'nin dağılımının normal dağılım olduğu varsayımı altında, OV etkin sınırı ile riskten kaçan yatırımcının tercihini bire bir yansıtan İkinci Dereceden Stokastik Baskınlık etkin sınırı özdeştir (Levy ve Robinson, 2016). Bu nedenle (1) ve (2)'den elde edilen etkin sınırlar özdeştir ve riskten kaçan yatırımcının tercih edebileceği tüm portföylerin kümesine eşittir. Burada $\lambda$ riskten kaçınma katsayısıdır ve nonnegatiftir.

$$
\operatorname{maks}_{w \in S} \mu_{p}-0.5 \lambda \sigma_{p}^{2}
$$

Portföyde risksiz varlık bulunabilsin. Buna göre etkin sınır, risksiz varlık ve aşağıda verilen piyasa portföyünün (PiyPor) lineer kombinasyonları ile elde edilebilir. Bu durum literatürde Tek Fon Teoremi olarak adlandırılır. Burada $\overline{1}$ tüm elemanları 1 olan sütun vektörüdür ve $f$ risksiz faiz oranını göstermektedir ve Bloomberg gösterge faizi olarak alınmıştır. Buna göre pay ve paydadaki parantez içindeki ifade ek ortalama vektörüne karşı gelir. PiyPor'un uzun veya kısa pozisyonu Sharpe Oranını (SO) maksimum yapar. SO, portföyün nonnegatif ek ortalamasının standart sapmaya bölünmesiyle bulunur. Burada ek ortalama negatifse SO tanımsızdır. 


$$
(\mu-f \overline{1})^{T} \Sigma^{-1} \overline{1} \neq 0 \Rightarrow \text { PiyPor }=\frac{\Sigma^{-1}(\mu-f \overline{1})}{(\mu-f \overline{1})^{T} \Sigma^{-1} \overline{1}}
$$

Portföyde risksiz varlık bulunmasın ve MinVarPor, varyansı minimum yapan portföy olsun. O zaman etkin sınır MinVarPor ile PiyPor'un lineer kombinasyonları ile elde edilebilir. Başka bir deyişle herhangi bir etkin portföy, bu iki portföyün belirli ağırlıklarla bir araya getirilmesiyle oluşturulabilir. Bu durum literatürde İki Fon Teoremi olarak adlandırılır.

$$
\text { MinVarPor }=\frac{\sum^{-1} \overline{1}}{\overline{1}^{T} \sum^{-1} \overline{1}}
$$

Bu çalışmada OV modeli parametrelerinin yansız tahmincileri kullanılmıştır. (Bunlar örneklem ortalama vektörü ve örneklem kovaryans matrisi olarak adlandırılır.) Bu yaklaşımla MinVarPor için yansız tahmin yapılmaktadır. Öte yandan normal dağılım varsayımı altında bile PiyPor'un beklenen değeri yoktur. Bu nedenle teorik önemine karşın uygulamada PiyPor kullanılırken dikkatli olunması faydalı olabilir (Okhrin ve Schmid, 2006). Bununla birlikte ortalama vektörünün tahminindeki istatistiksel hata, kovaryans matrisin tahminindeki istatistiksel hatadan çok daha yüksek olduğundan MinVarPor, PiyPor'a göre örneklem dışı analizlerde daha başarılı sonuçlar verebilmektedir (De Miguel ve diğerleri, 2009).

\section{AHS ile Portföy Seçimi ve Önerilen Hibrit Yaklaşım}

AHS ile portföy seçimi yapılırken başka bir deyişle AHSPor oluşturulurken Saaty ve diğerleri (1980) ve Tiryaki ve Ahlatçığlu (2009)'daki kriterler kullanılabilir. Buna karşın bu çalışmada aşağıdaki 
kriterlerle AHSPor oluşturulmuştur. Uzun dönemli yatırım kararlarında bu kriterlere, uzun dönemde maliyetin sıfırlanma hızı ile ilişkili olan temettü verimi de eklenebilir.

$>$ Ucuzluk göstergesi olarak piyasa değeri bölü defter değeri oranı. (Kısaca PD/DD olarak gösterilir.)

> Karlılık göstergesi olarak özsermaye karlılığı.

> Breuer ve diğerleri (2010)'da incelenen piyasa riski ile kredi riski arasındaki pozitif yönlü etkileşimden dolayı kredi notu.

$>$ Likit olma derecesinin göstergesi olarak tahmini işlem hacmi. Alternatif göstergeler ile ilgili bilgi için Akar (2015)'e bakınız.

Beklenen performans göstergesi olarak Sharpe Oranı.

AHSPor bulunurken aşağıdaki adımlar izlenir. AHS ile ilgili detaylı bilgi için Saaty (2003) ve Saaty ve Vargas (2012)’ye bakınız.

$>$ Kriterlerin amaca göre, alternatiflerin ise kritere göre pozitif değerli ikili karşılaştırma matrisleri oluşturulur. Bunların köşegeni üzerindeki elemanları 1 iken köşegenine göre simetrik elemanları birbirlerinin çarpmaya göre tersidir. Kriterlerin amaca göre ikili karşılaştırmalarında kullanılan ölçekte; eşit derecede önemli 1 ile, biraz daha önemli 3 ile, önemli 5 ile, fazla önemli 7 ile, aşırı derecede önemli 9 ile gösterilir. Arada kalmış durumlar ise karşı gelen ara değer (2, 4, 6 veya 8) ile gösterilir. Alternatiflerin kritere göre ikili karşılaştırmalarında bu bilgiler korunmakla beraber "önem" yerini “üstünlüğe” bırakır.

> İkili karşılaştırma matrisinin mutlak değerce maksimum olan özdeğerine (Perron köküne) karşı gelen ve elemanları toplamı 
1 olan özvektör (Perron vektörü) tek olarak bulunur. Bu vektörün elemanları, Perron kökü gibi pozitiftir.

> Kriterlerin ağırlıkları, amaca göre oluşturulan ikili karşılaştırma matrisinin Perron vektörüne eşit alınır.

> Kriterlere göre oluşturulan ikili karşılaştırma matrislerinden elde edilen Perron vektörleri ile kriterlerin ağırlığı ayrı ayrı çarpilır.

> Daha sonra elde edilen vektör değerleri toplanır ve buradan elde edilen sonuç öncelik vektörü olarak atanır. AHSPor, tüm elamanları pozitif olan öncelik vektörüne eşit alınır.

Portföy seçiminde AHS'nin doğrudan kullanılmasının temel eksiklikleri, kısa pozisyona izin vermemesi ve alternatiflerin (hisse senetlerinin) lineer korelasyon yapısının dikkate alınamamasıdır. Öte yandan AHSPor'un bulunmasındaki adımlar performans kriteri için elde edilen Perron vektörü yerine PiyPor'un kullanılması dışında izlenirse bu kez ideal portföy (İdealPor) oluşturulur. Önerilen bu yaklaşım ilk eksikliği kısmen, ikincisini ise tamamen ortadan kaldırır. Ayrıca bu yaklaşım kantitatif analiz ile temel analizi de birleştirir.

\section{BIST 30'daki Bankacılık Hisseleri Üzerine Bir Uygulama}

Bu bölümde Garanti Bankası (GARAN), Yapı Kredi Bankası (YKBNK), Halk Bankası (HALKB), AKBANK (AKBNK) ve İş Bankası (ISCTR) hisselerinin 2016 Ekim'den, 2017 Kasım'a kadarki aylık verileri kullanılarak önerilen portföy seçim yaklaşımı tanıtılmıştır. Ayrıca önerilen bu yaklaşımın ve literatürdeki alternatiflerinin geriye dönük test sonuçları, 2017 Kasım ve Aralık dönemi için karşılaştırılmıştır. Burada 2017 yılı üçüncü çeyrek bilançosunu, 2017 
Ekim ayı içinde göndermediğinden Vakıfbank (VAKBN) hissesi değerlendirme dişı tutulmuştur.

2017 Kasım ve Aralık dönemi için ilgili hisselerle ilgili ek ortalama (EO), standart sapma (SS) ve Sharpe Oranı (SO) öngörüleri aşağıdaki gibidir. Görüldüğü üzere en olumlu öngörüler ISCTR hissesi hakkındadır.

Tablo 1: Hisseler Hakkındaki Öngörüler

\begin{tabular}{cccccc}
\hline \hline & GARAN & YKBNK & HALKB & AKBNK & ISCTR \\
\hline EO & 0.027 & 0.015 & 0.012 & 0.018 & 0.049 \\
SS & 0.103 & 0.120 & 0.152 & 0.084 & 0.087 \\
SO & 0.259 & 0.123 & 0.079 & 0.212 & 0.558 \\
\hline \hline
\end{tabular}

Aşağıdaki tabloda bunların pozitif tanımlı lineer korelasyon matrisinin tahmincisi verilmiştir. Buna göre bu hisselerin logaritmik getirileri arasında pozitif yönlü lineer ilişki vardır.

Tablo 2: Lineer Korelasyon Matrisi

\begin{tabular}{cccccc}
\hline \hline & GARAN & YKBNK & HALKB & AKBNK & ISCTR \\
\hline GARAN & 1 & 0.323 & 0.663 & 0.968 & 0.826 \\
YKBNK & 0.323 & 1 & 0.452 & 0.293 & 0.409 \\
HALKB & 0.663 & 0.452 & 1 & 0.730 & 0.711 \\
AKBNK & 0.968 & 0.293 & 0.730 & 1 & 0.860 \\
ISCTR & 0.826 & 0.409 & 0.711 & 0.860 & 1 \\
\hline \hline
\end{tabular}

Alternatif hisselerin kriter bazındaki bilgilerinin bulunduğu değerlendirme matrisi aşağıdaki gibidir. Buradaki kredi notu, ilgili 
bankalara Fitch tarafından verilen ve 31 Ekim 2017 itibariyle güncel olan TL cinsinden kisa vadeli nottur. F3 ve B, yedi adet olan Fitch'in kısa vadeli kredi notları içinde sırasıyla üçüncü ve dördüncü sıradadır. Tahmini işlem hacmi ise eğitim periyodundaki medyan aylık işlem hacminin iki katı olarak alınmıştır ve milyar TL olarak verilmiştir.

Tablo 3: Değerlendirme Matrisi

\begin{tabular}{cccccc}
\hline \hline & PD/DD & $\begin{array}{c}\text { Özsermaye } \\
\text { Karlılı̆̆1 }\end{array}$ & $\begin{array}{c}\text { Kredi } \\
\text { Notu }\end{array}$ & $\begin{array}{c}\text { Tahmini } \\
\text { İşlem } \\
\text { Hacmi }\end{array}$ & $\begin{array}{c}\text { Sharpe } \\
\text { Oranı }\end{array}$ \\
\hline GARAN & 1.11 & 0.147 & F3 & 28.161 & 0.259 \\
YKBNK & 0.69 & 0.114 & F3 & 4.959 & 0.123 \\
HALKB & 0.58 & 0.135 & F3 & 11.370 & 0.079 \\
AKBNK & 1.03 & 0.144 & B & 8.789 & 0.212 \\
ISCTR & 0.78 & 0.133 & B & 6.140 & 0.558 \\
\hline \hline
\end{tabular}

Portföy seçimi için oluşturulan hiyerarşi aşağıdaki gibidir. Buna göre alternatifler kriterleri, kriterler amacı etkilemektedir. Bunun dışında tek yönlü veya karşılıklı herhangi bir etki yoktur. Bu tür etkilerin olması halinde ise portföy seçiminde Saaty (2004)'te verilen Analitik Ağ Süreci kullanılabilir. 


\section{Grafik 1: Portföy Seçimi Hiyerarşisi}

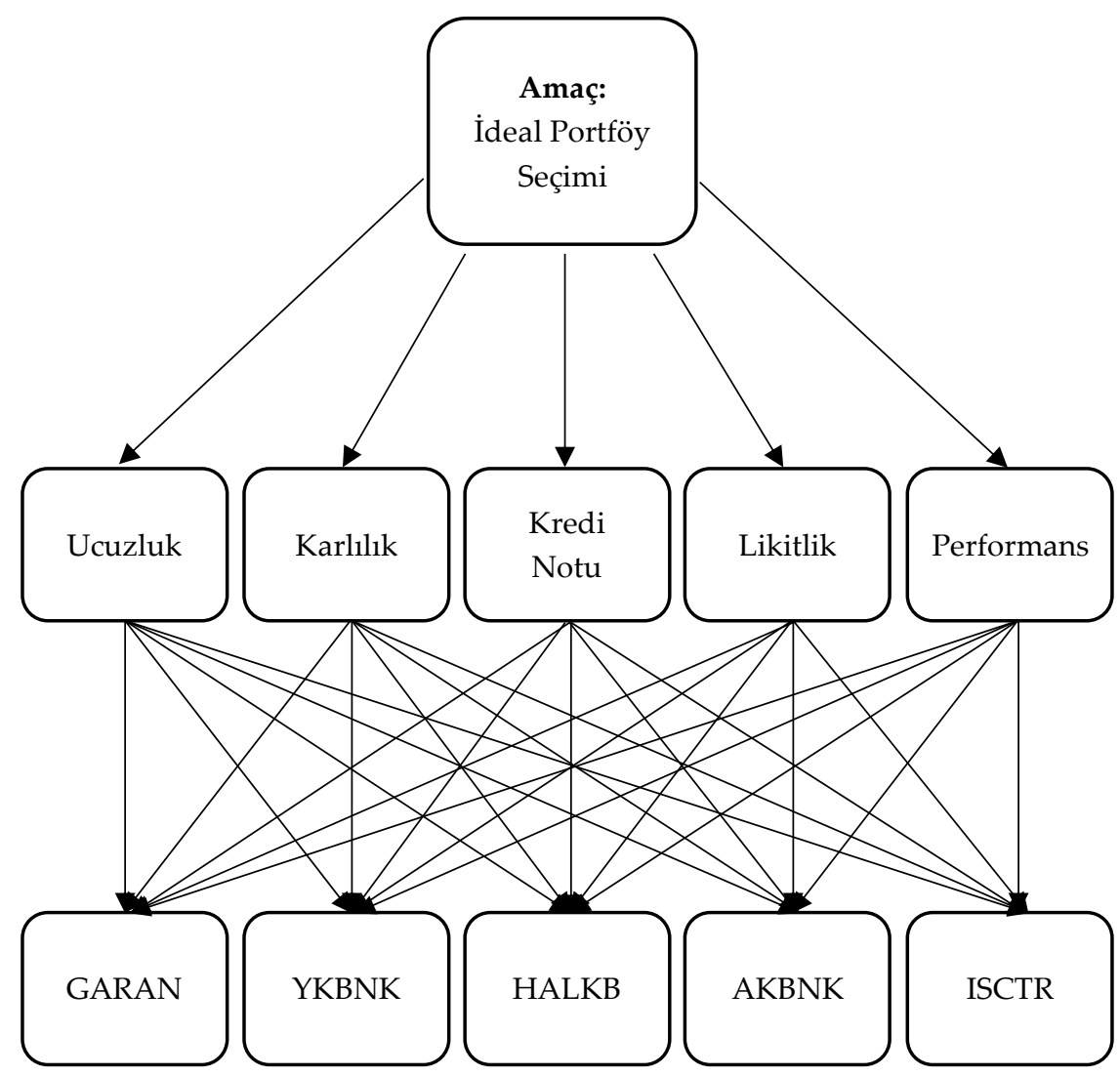

İdeal portföy seçimi için kriterlerin ikili karşılaştırma matrisi ve bunun Perron vektörü aşağıdaki gibidir. Bu matrisin Perron kökü 5.136, tutarlılık indeksi 0.030 olarak bulunmuştur. (Literatürde belirli formüllerle bunlar için yaklaşık değerler hesaplanması yaygındır. $\mathrm{Bu}$ çalışmada ise gerçek değerler, MATLAB programı ile hesaplanmıştır. Böylece portföydeki varlıkların ağırlıkları çok daha doğru bir şekilde belirlenmiştir.) Burada bulunan 0.030, değerlendirmelerin tutarlı kabul edilebilmesi için üst sınır olan 0.10'dan küçüktür. Başka bir deyişle yapılan ikili karşılaştırmalar tutarlıdır. Tutarlılık indeksi ile ilgili detaylı bilgi için Saaty ve Vargas (2012)'ye bakınız. 
Tablo 4: Amaç İçin İkili Karşılaştıma Matrisi

\begin{tabular}{ccccccc}
\hline \hline & Ucuzluk & Karlılık & $\begin{array}{c}\text { Kredi } \\
\text { Notu }\end{array}$ & Likitlik & Performans & $\begin{array}{c}\text { Perron } \\
\text { V. }\end{array}$ \\
\hline Ucuzluk & 1 & $1 / 3$ & 5 & 5 & 3 & 0.258 \\
Karlılık & 3 & 1 & 7 & 7 & 5 & 0.514 \\
Kredi Notu & $1 / 5$ & $1 / 7$ & 1 & 1 & $1 / 3$ & 0.053 \\
Likitlik & $1 / 5$ & $1 / 7$ & 1 & 1 & $1 / 3$ & 0.053 \\
Performans & $1 / 3$ & $1 / 5$ & 3 & 3 & 1 & 0.122 \\
\hline \hline
\end{tabular}

Ucuzluk kriteri için alternatiflerin ikili karşılaştırma matrisi ve bunun Perron vektörü aşağıdaki gibidir. Bu matrisin Perron kökü 5.205, tutarlılık indeksi 0.046 olarak bulunmuştur. Başka bir deyişle yapılan ikili karşılaştırmalar tutarlıdır.

Tablo 5: Ucuzluk Kriteri İçin İkili Karşılaştıma Matrisi

\begin{tabular}{ccccccc}
\hline \hline & GARA & YKBN & HALK & AKBN & ISCT & Perro \\
& $\mathrm{N}$ & $\mathrm{K}$ & $\mathrm{B}$ & $\mathrm{K}$ & $\mathrm{R}$ & $\mathrm{n} \mathrm{V}$. \\
\hline GARA & 1 & $1 / 7$ & $1 / 9$ & 1 & $1 / 5$ & 0.038 \\
YKBNK & 7 & 1 & $1 / 3$ & 7 & 3 & 0.267 \\
HALKB & 9 & 3 & 1 & 9 & 5 & 0.519 \\
AKBNK & 1 & $1 / 7$ & $1 / 9$ & 1 & $1 / 5$ & 0.038 \\
ISCTR & 5 & $1 / 3$ & $1 / 5$ & 5 & 1 & 0.137 \\
\hline \hline
\end{tabular}

Karlılık kriteri için alternatiflerin ikili karşılaştırma matrisi ve bunun Perron vektörü aşağıdaki gibidir. Bu matrisin Perron kökü 5.026, tutarlılık indeksi 0.005 olarak bulunmuştur. Başka bir deyişle yapılan ikili karşılaştırmalar tutarlıdır. 
Tablo 6: Karlılık Kriteri İçin İkili Karşılaştıma Matrisi

\begin{tabular}{ccccccc}
\hline \hline & GARA & YKBN & HALK & AKBN & ISCT & Perro \\
& $\mathrm{N}$ & $\mathrm{K}$ & $\mathrm{B}$ & $\mathrm{K}$ & $\mathrm{R}$ & $\mathrm{n} \mathrm{V}$. \\
\hline GARA & 1 & 4 & 2 & 1 & 2 & 0.303 \\
YKBNK & $1 / 4$ & 1 & $1 / 3$ & $1 / 4$ & $1 / 3$ & 0.065 \\
HALKB & $1 / 2$ & 3 & 1 & $1 / 2$ & 1 & 0.164 \\
AKBNK & 1 & 4 & 2 & 1 & 2 & 0.303 \\
ISCTR & $1 / 2$ & 3 & 1 & $1 / 2$ & 1 & 0.164 \\
\hline \hline
\end{tabular}

Kredi notu kriteri için alternatiflerin ikili karşılaştırma matrisi ve bunun Perron vektörü aşağıdaki gibidir. Bu matrisin Perron kökü 5, tutarlılık indeksi 0.000 olarak bulunmuştur. Başka bir deyişle yapılan ikili karşılaştırmalar tutarlıdır.

Tablo 7: Kredi Notu Kriteri İçin İkili Karşılaştıma Matrisi

\begin{tabular}{ccccccc}
\hline \hline & GARA & YKBN & HALK & AKBN & ISCT & Perro \\
& $\mathrm{N}$ & $\mathrm{K}$ & $\mathrm{B}$ & $\mathrm{K}$ & $\mathrm{R}$ & $\mathrm{n} \mathrm{V}$. \\
\hline GARA & 1 & 1 & 1 & 3 & 3 & 0.273 \\
YKBNK & 1 & 1 & 1 & 3 & 3 & 0.273 \\
HALKB & 1 & 1 & 1 & 3 & 3 & 0.273 \\
AKBNK & $1 / 3$ & $1 / 3$ & $1 / 3$ & 1 & 1 & 0.091 \\
ISCTR & $1 / 3$ & $1 / 3$ & $1 / 3$ & 1 & 1 & 0.091 \\
\hline \hline
\end{tabular}

Likitlik kriteri için alternatiflerin ikili karşılaştırma matrisi ve bunun Perron vektörü aşağıdaki gibidir. Bu matrisin Perron kökü 5.189, tutarlılık indeksi 0.042 olarak bulunmuştur. Başka bir deyişle yapılan ikili karşılaştırmalar tutarlıdır. 
Tablo 8: Likitlik Kriteri İçin İkili Karşılaştıma Matrisi

\begin{tabular}{ccccccc}
\hline \hline & $\begin{array}{c}\text { GARA } \\
\mathrm{N}\end{array}$ & $\begin{array}{c}\text { YKBN } \\
\mathrm{K}\end{array}$ & $\begin{array}{c}\text { HALK } \\
\mathrm{B}\end{array}$ & $\begin{array}{c}\text { AKBN } \\
\mathrm{K}\end{array}$ & $\begin{array}{c}\text { ISCT } \\
\mathrm{R}\end{array}$ & $\begin{array}{c}\text { Perro } \\
\mathrm{n} \mathrm{V} .\end{array}$ \\
\hline GARA & 1 & 9 & 5 & 7 & 8 & 0.602 \\
YKBNK & $1 / 9$ & 1 & $1 / 5$ & $1 / 3$ & $1 / 2$ & 0.040 \\
HALKB & $1 / 5$ & 5 & 1 & 3 & 4 & 0.202 \\
AKBNK & $1 / 7$ & 3 & $1 / 3$ & 1 & 2 & 0.094 \\
ISCTR & $1 / 8$ & 2 & $1 / 4$ & $1 / 2$ & 1 & 0.061 \\
\hline \hline
\end{tabular}

Performans kriteri için alternatiflerin ikili karşılaştırma matrisi ve bunun Perron vektörü aşağıdaki gibidir. Bu matrisin Perron kökü 5.198, tutarlılık indeksi 0.045 olarak bulunmuştur. Başka bir deyişle yapılan ikili karşılaştırmalar tutarlıdır.

Tablo 9: Performans Kriteri İçin İkili Karşılaştıma Matrisi

\begin{tabular}{ccccccc}
\hline \hline & GARA & YKBN & HALK & AKBN & ISCT & Perro \\
& $\mathrm{N}$ & $\mathrm{K}$ & $\mathrm{B}$ & $\mathrm{K}$ & $\mathrm{R}$ & $\mathrm{n} \mathrm{V}$. \\
\hline GARA & 1 & 4 & 5 & 2 & $1 / 5$ & 0.188 \\
YKBNK & $1 / 4$ & 1 & 2 & $1 / 3$ & $1 / 8$ & 0.057 \\
HALKB & $1 / 5$ & $1 / 2$ & 1 & $1 / 4$ & $1 / 9$ & 0.039 \\
AKBNK & $1 / 2$ & 3 & 4 & 1 & $1 / 6$ & 0.124 \\
ISCTR & 5 & 8 & 9 & 6 & 1 & 0.593 \\
\hline \hline
\end{tabular}

Tablo 4'teki Perron vektörü, ideal portföy seçimi probleminde kriterlerin ağırlıklarını göstermektedir. Bunlar ilgili kriterler için elde edilen Perron vektörleri ile çarpılır ve daha sonra bu vektör değerleri toplanır. Bu toplamsa AHS'nin öncelik vektörü olarak atanır. Bu 
işlemler sırasıyla yapılmış ve öncelik vektörüne eşit alınan AHSPor, Tablo 10'daki gibi bulunmuştur. Ayrıca AHS'nin birleştirme ve sentez işleminde performans kriteri için Tablo 9'daki Perron vektörü yerine PiyPor'un kullanılması ile İdealPor, Tablo 10'daki gibi oluşturulmuştur. Görüldüğü üzere AHSPor'da tanımı gereği kısa pozisyon yoktur. İdealPor'da, PiyPor'un etkisiyle AKBNK hissesinin kisa pozisyonu bulunmaktadır.

Tablo 10: Portföylerin Ağırlık Vektörleri

\begin{tabular}{ccccc}
\hline \hline & PiyPor & MinVarPor & AHSPor & İdealPor \\
\hline GARAN & 3.226 & -1.506 & 0.251 & 0.608 \\
YKBNK & -0.163 & 0.008 & 0.116 & 0.088 \\
HALKB & -0.369 & -0.270 & 0.258 & 0.193 \\
AKBNK & -7.450 & 2.481 & 0.228 & -0.725 \\
ISCTR & 5.755 & 0.287 & 0.152 & 0.836
\end{tabular}

2017 Kasım ve Aralık dönemi için ilgili portföylerle ilgili ek ortalama (EO), standart sapma (SS) ve Sharpe Oranı (SO) öngörüleri aşağıdaki gibidir.

Tablo 11: Test Periyodu İçin Beklentiler

\begin{tabular}{ccccc}
\hline \hline & PiyPor & MinVarPor & AHSPor & İdealPor \\
\hline EO & 0.228 & 0.015 & 0.023 & 0.048 \\
SS & 0.256 & 0.065 & 0.132 & 0.129 \\
SO & 0.888 & 0.226 & 0.173 & 0.370 \\
\hline \hline
\end{tabular}

$\mathrm{Bu}$ çalışmada iki farklı gerçekleşmiş performans ölçüsü tanımlanmıştır. Birinci ölçü (Ö1) risksiz faiz oranı üzerindeki getiri 
(GG) bölü standart sapma olarak alınmıştır ve Sharpe Oranı ile ilişkilidir. İkinci ölçü (Ö2) eşit ağırlıklı portföyün getirisi üzerindeki getiri bölü standart sapma olarak olarak alınmıştır. Sharpe Oranı gibi bu iki ölçü de formüllerindeki pay ifadesi pozitif iken tanımlıdır.

Aşağıda test periyodu için gerçekleşmiş sonuçlar verilmiştir. Görüldüğü üzere PiyPor en iyi sonuçlara sahip iken, İdeal portföy ise en iyi ikinci sonuçlara sahiptir.

Tablo 12: Geriye Dönük Test Sonuçları

\begin{tabular}{ccccc}
\hline \hline & PiyPor & MinVarPor & AHSPor & İdealPor \\
\hline GG & 0.068 & -0.102 & -0.034 & -0.022 \\
Ö1 & 0.268 & Tanımsız & Tanımsız & Tanımsız \\
Ö2 & 0.422 & Tanımsız & 0.042 & 0.136 \\
\hline \hline
\end{tabular}

\section{Sonuç ve Değerlendirme}

Portföy seçiminde OV modeli gibi kantitatif yaklaşımlar ve temel analiz genellikle birbirlerine alternatif olarak görülür. Öte yandan bu çalışmada temel analizin, kantitatif analizle birlikte portföy seçiminde kullanılmasını sağlayan hibrit bir yaklaşımı önerilmiştir. Bu yaklaşıma göre Modern Portföy Teorisi ile ilişkili olan performans kriteri ile birlikte ucuzluk, karlılık, kredi notu ve likitlik kriterleri de portföy seçiminde kullanılmıştır. Önerilen hibrit yaklaşım AHS ile portföy seçimiyle tek bir nokta dışında özdeştir. Bu farklılık, performans kriteri için ikili karşılaştırma matrisinin Perron vektörü yerine piyasa portföyünün (PiyPor) kullanılmasıdır. Böylece hisse senetlerinin lineer korelasyon yapısı dikkate alınabilmiş ve kısa 
pozisyon içeren ideal portföy (İdealPor) oluşturulabilmiştir. Yapılan uygulamada İdealPor'un tatmin edici sonuçlar verdiği görülmüştür. Öte yandan yapılan uygulamada örneklem dışı analiz olmadığından bu sonuçlar genelleştirilemez.

\section{KAYNAKÇA}

Akar, C. (2015). Türkiye Hisse Senedi Piyasasında Likidite Ölçülerinin Karşılaştırılması ve Likidite Volatilitesi Hisse Senedi Getirisi Arasındaki İlişki. Yönetim ve Ekonomi: Celal Bayar Üniversitesi İktisadi ve İdari Bilimler Fakültesi Dergisi, 22(1), 31-48.

Breuer, T. (2006). Providing Against the Worst: Risk Capital for Worst Case Scenarios. Managerial Finance, 32(9), 716-730.

Breuer, T., Jandacka, M., Rheinberger, K. ve Summer, M. (2010). Does Adding Up of Economic Capital for Market and Credit Risk amount to Conservative Risk Assessment? Journal of Banking \& Finance, 34(4), 703-712.

Brigo, D., Dalessandro, A., Neugebauer, M. ve Triki, F. (2007). A Stochastic Processes Toolkit for Risk Management.

De Miguel, V., Garlappi, L., Nogales, F. J., ve Uppal, J. (2009). A Generalized Approach to Portfolio Optimization: Improving Performance by Constraining Portfolio Norms, Management Science, 55(5), $798-812$.

Deb, K. (2001). Multi-Objective Optimization Using Evolutionary Algorithms. Wiley. 
Garlappi, L., Uppal, R. ve Wang, T. (2006). Portfolio Selection with Parameter and Model Uncertainty: A Multi-prior Approach. The Review of Financial Studies, 20(1), 41-81.

Jorion, P. (2007). Value at Risk. - The New Benchmark for Managing Financial Risk. McGraw-Hill.

Levy, H. ve Robinson, M. (2016). Stochastic Dominance: Investment Decision Making Under Uncertainty. Springer.

Markowitz, H. (1952). Portfolio Selection. The Journal of Finance, 7(1), 77-91.

Okhrin, Y. ve Schmid, W. (2006). Distributional Properties of Portfolio Weights, Journal of Econometrics, 134(1), 235-256.

Saaty, T. L. (2003). Decision Making with the AHP: Why is the Principal Eigenvector Necessary. European Journal of Operational Research, 145(1), 85-91.

Saaty, T. L. (2004). Decision Making - The Analytic Hierarchy and Network Processes (AHP/ANP). Journal of Systems Science and Systems Engineering, 13(1), 1-35.

Saaty, T. L., Rogers, P. C. ve Pell, R. (1980). Portfolio Selection Through Hierarchies. The Journal of Portfolio Management, 6(3), 16-21.

Saaty, T. L. ve Vargas L. G. (2012). Models, Methods, Concepts $\mathcal{E}$ Applications of The Analytical Hierarchy Process. Springer.

Tiryaki, F. ve Ahlatcioglu, B. (2009). Fuzzy Portfolio Selection Using Fuzzy Analytic Hierarchy Process. Information Sciences, 179(1), 53-69. 